SJ Quinney College of Law, University of Utah

Utah Law Digital Commons

Utah Law Faculty Scholarship

Utah Law Scholarship

$2-2020$

Debunking the Myths Behind the NEPA Review Process

John C. Ruple

Heather Tanana

Follow this and additional works at: https://dc.law.utah.edu/scholarship

Part of the Environmental Law Commons, Natural Resources Law Commons, and the Oil, Gas, and Mineral Law Commons 
** Pre-Publication Draft **

35 Natural Resources \& Environment (2020)

\title{
Debunking the Myths Behind the NEPA Review Process
}

\author{
John Ruple \\ Heather Tanana
}

Our fathers grew up thousands of miles apart—one in a traditional hogan on the Navajo reservation, and the other under the city lights in Seattle. They nonetheless imparted on us similar fatherly wisdom: don't sacrifice your long-term goals by chasing fads; cheap is not the same as inexpensive; and, most importantly for this article, don't believe everything that you hear. When it comes to the National Environmental Policy Act (NEPA), we took these lessons to heart. Conventional wisdom is that NEPA compliance is unduly burdensome; NEPA litigation is an overused cudgel for environmentalists; and NEPA unreasonably delays much needed projects, thereby hurting the economy. Recalling our fathers' words, we found ourselves searching for the data and studies to support conventional wisdom. Finding little beyond anecdotes, we set out to answer a very basis question: does rhetoric reflect reality? We conclude that it does not. What follows is a summary of what we found respecting several pervasive criticisms.

\section{An Overview of the National Environmental Policy Act}

NEPA was signed into law on January 1, 1970, on the heels of the Santa Barbara oil spill, which spread oil across hundreds of miles of pristine California beaches. NEPA also followed shortly after the Cuyahoga River in Ohio burst into flames (for the thirteenth time), and publication of Rachel Carson's book, Silent Spring, documenting how DDT and other pesticides nearly led to the Bald Eagle's extinction. NEPA's enactment reflected a national consensus that federal law and policy had largely ignored the need to protect aesthetic and ecological values.

NEPA begins by declaring that, as a matter of national policy, the federal government "will encourage productive and enjoyable harmony between man and his environment; to promote efforts which will prevent or eliminate damage to the environment and biosphere and stimulate the health and welfare of man; [and] to enrich the understanding of the ecological systems and natural resources important 
to the Nation[.]" 42 U.S.C. $§ 4321$. While other environmental laws focus on a particular media such as water or air, NEPA defines the process for federal agencies making decisions affecting the environment. NEPA requires that agencies take a hard look at potential impacts before acting, and that the public have an opportunity to offer input before those decisions are made.

Under NEPA, "major federal actions significantly affecting the quality of the human environment" must undergo an environmental review before those actions can proceed. 43 U.S.C. $\S 4332(2)(C)$. The decision to license or permit a project on federal land is generally considered a major federal action. When a federal project's impacts are known to be significant in terms of their context and intensity, compliance requires completion of an Environmental Impact Statement (EIS). But EISs are rare, accounting for less than 1\% of all NEPA actions. Most actions undergo expedited review. U.S. Gov't Accountability Office, GAO-14-370, National Environmental Policy Act: Little Information Exists on NEPA Analysis 8 (2014).

When EISs are required, they are prepared in stages. At the outset of the NEPA process, the lead agency publishes a Notice of Intent to Prepare an EIS (NOI) in the Federal Register. The NOI describes the action contemplated, as well as the reasons for the action, and invites public comments on environmental issues raised by the proposed action as well as alternate means of achieving project goals. After considering public comment, the lead agency prepares a Draft EIS analyzing the direct, indirect, and cumulative impacts of both the proposed action and one or more alternative means of achieving the desired end. The Draft EIS compares the impacts projected to result from each alternative against the impacts that would result from a continuation of the status quo (the "no action alternative"). After another public comment period, and any appropriate revisions, a Final EIS and Record of Decision (ROD) are issued. If significant deficiencies are identified in a Draft or Final EIS, the lead agency may prepare a Revised or Supplemental EIS.

Most federal actions do not involve significant environmental impacts and therefore do not require an EIS. NEPA authorizes agencies to promulgate regulations specifying "Categorical Exclusions" (CEs) - categories of actions that the agency determines do not individually or cumulatively have a significant impact on the human environment. Actions that fall within one of these regulatory CEs can be approved without an EIS, provided that the action does not involve "extraordinary circumstances." 40 C.F.R. $§ 1508.4$. Congress has also created 
statutory CEs for certain types of oil and natural gas development. See e.g., Energy Policy Act, 42 U.S.C. $§ 15942$.

Actions falling outside the scope of a $\mathrm{CE}$ can still avoid preparation of an EIS if a federal agency prepares an Environmental Assessment (EA) determining that the proposed action would not cause significant impacts. If projected impacts are not significant, the agency issues a Finding of No Significant Impact (FONSI) and the NEPA review process is complete. Alternatively, the agency may issue a "mitigated FONSI," which includes measures to reduce impacts to below the level of significance. If the proposed action is determined to have a significant effect, however, an EIS is required. Most federal actions do not require completion of an EIS because a CE applies, or they are determined in an EA not to have significant environmental impacts.

\section{Myth 1: NEPA review delays federal decision making}

Under NEPA, the amount of time and effort spent evaluating environmental impacts is proportionate to the scale of the anticipated impacts. Ninety-five percent of actions that trigger NEPA review are addressed in a CE. The fastest and least burdensome level of NEPA analysis, CEs require a matter of days to several months to approve. About $5 \%$ of actions requiring NEPA review involve an intermediate level of scrutiny and require an EA, which take from one to eighteen months to complete. EISs are reserved for the projects that have the greatest impacts (e.g., large logging operations, interstate or international oil pipelines, and airport expansions) and account for less than 1\% of all NEPA actions. The White House Council on Environmental Quality (CEQ) reports that the median completion time for an EIS is 3.6 years. GAO-14-370 at 8 .

Conceptually, different timeframes to complete different levels of review makes sense. Rational decisionmakers increase their level of scrutiny as the stakes rise. The federal government is doing the same thing with the resources charged to its care by reserving EISs for federal actions involving the highest level of environmental impact, scientific complexity, and public concern. And while critics frequently deride the long completion times for these most searching reviews, the multi-year review process is often attributable to factors outside of the lead agency's control, such as: lack of funding, project complexity, higher agency priorities, changes in scope of the project, engineering requirements, and delays in obtaining nonfederal approvals. See e.g., GAO-14-370 at 15,19. 
But we can dig deeper. To better understand NEPA in action and the burden of NEPA compliance, we reviewed 607 federal rules designating critical habitat for species that are protected under the Endangered Species Act. Because of conflicting Circuit Court opinions on NEPA's applicability to critical habitat designation, some of these designations underwent NEPA review while others did not. Designations that were subject to NEPA review were completed on average three months faster than those that were exempted from NEPA. John C. Ruple, Michael J. Tanana, and Merrill M. Williams, Does NEPA Help or Harm ESA Critical Habitat Designations? An Assessment of Over 600 Critical Habitat Rules, 46 ECOLOGY L. Q. _ (2020). This is not to say that the time spent on NEPA compliance is inconsequential, only that a NEPA review does not appear to delay federal decision making, and that the NEPA process may create a vehicle for coordinating other permitting decisions to improve overall permitting efficiency.

\section{Myth 2: NEPA's benefits are illusory and unreasonably costly}

The U.S. Supreme Court has consistently stated that NEPA is a procedural statute under which the agency must take a requisite "hard look" at likely impacts before rendering a decision. See e.g., Vermont Yankee Nuclear Power Corp. $v$ Natural Resources Defense Council, 435 U.S. 519 (1978); Robertson v. Methow Valley Citizens Council, 490 U.S. 332, 350 (1989). With the focus placed squarely on NEPA's procedural mandate, the question becomes whether the process produces a better result than what would have occurred but for NEPA.

To begin answering this question we looked at every EISs for Resource Management Plans (16 total) completed by the BLM in Colorado, Montana, Utah, and Wyoming between January 2004 and October 2014. John Ruple \& Mark Capone, NEPA, FLPMA, and Impact Reduction: An Empirical Assessment of BLM Resource Management Planning in the Mountain West, 46 ENVTL. L. 101 (2016). We also looked at every EIS completed by the BLM for large oil and gas development projects over that same region and period (13 total). John Ruple \& Mark Capone, NEPA-Substantive Effectiveness Under a Procedural Mandate: Assessment of Oil and Gas EISs in the Mountain West, 7 GEO. WASH. J. ENERGY \& ENVTL. L. 39 (2016).

The limited number of EISs for oil and gas development projects surprised us because oil and gas production was booming during that period. From 2004 through 2014, between 1,095 and 1,871 drill rigs were operating onshore each year, 
U.S. Energy Info. Admin, U.S. Onshore Crude Oil and Natural Gas Rotary Rigs in Operation. From 2009 through 2014 (the period of available data), 34.6 to 45.4 million acres of federal land was under lease for oil and gas development. U.S. Dept. of the Interior, Bureau of Land Management, Oil and Gas Statistics, Table 2 Acreage in Effect. This data affirms the point made above-EISs are rare, and most projects, even some very large projects, are authorized in EAs or CEs.

In reviewing those $29 \mathrm{EISs}$, we compared the impacts anticipated under the No Action Alternative in the Draft EIS (continuation of current management practices) to what was authorized in the ROD. The difference between the two iterations allowed us to measure the change that occurred during the NEPA process and to determine whether NEPA reduced environmental impacts. For the oil and gas EISs, we found that impacts to all measured indicators were reduced between the Draft EIS and the ROD. Statistically significant reductions $(\mathrm{p}<.05$ one-tailed) occurred for surface disturbance and $\mathrm{NO}_{\mathrm{X}}$ emission (both $-24 \%$ ). Reductions in the number of wells drilled $(-<1 \%)$, miles of pipeline built $(-2 \%)$, and emission of $\mathrm{PM}_{10}$ $(-23 \%)$ and $\mathrm{PM}_{2.5}(-24 \%)$ were all trending towards significance $(\mathrm{p}<.10$ onetailed). Impacts to wetlands were reduced dramatically between the Draft EIS and the ROD, though these reductions were not statistically significant.

Our analysis also indicates that the BLM remained focused on the most significant issues, which is precisely what NEPA directs. $\mathrm{NO}_{\mathrm{x}}, \mathrm{PM}_{10}$, and $\mathrm{PM}_{2.5}$ emissions as well as wetland impacts are all common concerns associated with oil and gas development, and all experienced large reductions. In contrast $\mathrm{SO}_{2}$ and $\mathrm{CO}$, which are subject to action-forcing regulation under the Clean Air Act, both experienced comparatively minor impact reductions $(-5 \%)$. Lower rates of emission reduction may indicate that agencies focus their efforts on pollutants of local concern (the project areas analyzed in these EISs generally have ambient $\mathrm{SO}_{2}$ and CO levels that are well below National Ambient Air Quality Standards). Such an approach is consistent with NEPA's mandate to focus on significant impacts. 40 C.F.R. $\S 1500.4(c)$.

We also found that transitioning towards directional drilling and consolidated well pads, a change that appears to have been driven by technological advancements and NEPA comments rather than a substantive environmental laws such as the Clean Air Act or Clean Water Act, resulted in 13\% reductions in permanent surface disturbance and $10 \%$ reductions in temporary surface 
disturbance. Both disturbance reductions were statistically significant, indicating that meaningful reductions can occur solely under NEPA's procedural mandate.

Critically, we found that for the oil and gas projects, job creation and state and local tax revenue increased in the face of enhanced environmental protections, though the rate of growth slowed as environmental protections increased. The BLM's Resource Management Plans faired similarly, producing a statistically significant increase in the application of more protective surface use stipulations without a significant change in either the projected number of jobs created, or the number of oil and gas wells that could be drilled. In fact, the number of jobs created and wells drilled increased by $8 \%$ and $2 \%$ respectively despite strengthened environmental protections. Overall, reductions in environmental impact were achieved without a corresponding reduction in economic benefit.

\section{Myth 3: NEPA review results in excessive litigation}

NEPA's detractors often charge that environmental activists have made NEPA litigation their weapon of choice in a systematic effort to stop or delay wideranging federal actions. This does not appear to be the case.

There is no single repository for NEPA decisions or even an accurate count of NEPA actions, so calculating the number of decisions that are made annually poses a challenge. We can, however, estimate the volume of NEPA decisions based on federal data. The EPA publishes notices of availability for all EISs and, as previously stated, less than $1 \%$ of NEPA actions involve an EIS. Extrapolating from those figures, we estimate that federal agencies generate roughly 52,000 NEPA decisions annually, possibly more.

While the number of NEPA decisions completed annually involves uncertainty, the number of NEPA decisions that are challenged in court does not. The CEQ maintained data on all NEPA litigation in federal court from 2001 through 2013. Over that period the CEQ documented 1,499 federal NEPA cases, or about 115 cases annually. Dividing the count of federal cases by our estimate of NEPA decisions indicates that only about 1 in every 450 NEPA decisions, or $0.22 \%$ of all NEPA decisions, result in litigation. John C. Ruple \& Kayla M. Race, Measuring the NEPA Litigation Burden: A Review of 1,499 Federal Court Cases, 50:2 ENVTL. L. _ (2020). To put that in perspective, during the 12-month period ending 
** Pre-Publication Draft **

Forthcoming at: 35 NATURAL RESOURCES \& ENVIRONMENT

(2020)

March 31, 2017, 9.78\% of all federal district court civil decisions were appealed, See Office of the U.S. Courts, Federal Judicial Caseload Statistics 2017.

The CEQ's data also shows a strong downward trend in NEPA litigation, with the last five years in our dataset all showing below average court filings. At the same time that NEPA litigation was falling, the number of civil suits handled annually by the U.S. Attorneys Office increased by over 14,000. NEPA challenges also fell faster than the rate at which agencies prepare EISs, which is also declining. We simply do not see in the data evidence that NEPA results in an excessive litigation given the low and declining rate at which NEPA decisions are challenged.

Other recent scholarship found that while environmental organizations are more likely to challenge a NEPA decision than other groups, environmentalists also prevail in litigation at a higher rate than other kinds of plaintiffs. David E. Adelman \& Robert L. Glicksman, Presidential and Judicial Politics in Environmental Litigation, 50 ARIZ. ST. L.J. 3, 22 (2018). This indicates that environmentalists, rather than being highly litigious, are quite selective in the cases that they elect to file.

We admit that when estimating the universe of NEPA decisions completed each year we are extrapolating from limited data, and our estimates may therefore be off-but we are using the best information currently available. This limitation, we believe, highlights the importance of obtaining better information about NEPA decisions. As a nation, we would not make decisions about national health or education policy based solely on anecdotal information, and decisions about environmental policy should be no different. As our fathers might say: you can't manage what you can't measure.

\section{Myth 4: "Streamlining" NEPA will reduce the time required for permit issuance}

Recent NEPA reform efforts focus on reducing the NEPA compliance burden by "streamlining" the NEPA process. Pending proposals involve page limits on NEPA documents, restricting the number of alternatives considered, and imposing strict time limits on the NEPA analysis.

While we agree that NEPA compliance can be improved, sacrifice quality for speed places agencies at risk. When reviewing a NEPA decision, courts consider both compliance with NEPA's procedural requirements, and whether the agency 
took the requisite "hard look" at likely impacts. Robertson, 490 U.S. at 350. The hard look standard grows not from NEPA's implementing regulations, but from section 101 of the Act itself. Section 101 is Congress' declaration of our national environmental policy, and it is axiomatic that an agency cannot change a policy that has been enacted into law by passing a contrary regulation. Streamlining efforts do not change the Supreme Court mandated standard of review. The question becomes whether agencies can consistently clear the same substantive hurdle in less time and with less space to document their analysis. We question whether that is possible and anticipate that pending streamlining proposals, if enacted, will backfire. If implemented, streamlining will likely increase the volume of litigation and the rate at which NEPA decisions are struck down in court, and that will delay federal decisions. The data supports this expectation.

Our colleagues David Adelman and Rob Glicksman recently calculated the number of EISs produced by an agency as a percent of EISs government-wide. They then calculated the agency's share of all EIS litigation. Combining these two figures results in a production to litigation ratio, where a ratio greater than one indicates a higher than average rate of NEPA litigation. Adelman \& Glicksman, at 30 . We built on their work by comparing the litigation ratio to the amount of time spent on the NEPA analysis and found that going fast increases the risk of litigation. The old adage, go slow to go fast, is borne out by the data.

Looking at the four federal agencies that prepared the largest number of EISs from 2010 through 2017, Adelman and Glicksman found that the Forest Service prepared 276 EISs and had a litigation ratio of 1.4, indicating that Forest Service EISs were challenged at a rate roughly $40 \%$ higher than that for all agencies government-wide. The Bureau of Land Management came in a distant second in terms of the number of EISs produced, accounting for 128 and a litigation ratio of 1.0. The Federal Highway Administration was almost as active, preparing 114 EISs over the study period, but doing so while generating a litigation ratio of just 0.3 . The Army Corps of Engineers prepared 89 EISs with a litigation ratio of 0.5. These ratios, when combined with the time spent on EIS preparation, tell a powerful story.

The less time an agency spent on EIS preparation the more likely it was to be sued. As noted above, median completion time for an EIS was 3.6 years. The BLM, with a litigation ratio of 1.0 was almost average, requiring 3.8 years to complete an EIS. The Forest Service cut approximately 7 months from EIS preparation time, but they did so at the expense of increased litigation. The Federal 


\section{** Pre-Publication Draft **}

Forthcoming at: 35 NATURAL RESOURCES \& ENVIRONMENT _ (2020)

Highway Administration and Army Corps of Engineers both spent considerably more time on EIS preparation and significantly reduced their risk of litigation. Rapid EIS preparation, in short, was more likely to result in litigation.

With NEPA litigation taking an average of 23 months to complete, Adelman $\&$ Glicksman at 38, gains in preparation time are likely to be more than offset by litigation related delays. We lack the data to say how the time spent on EIS preparation correlates with litigation outcomes, but we suspect that a rushed analysis increases the risk of an oversight or mistake. And an error resulting in court ordered revisions to a NEPA document will compound litigation related delays. The benefits gained by expediting NEPA may, in short, be subsumed by even greater costs for NEPA litigation and document revision. As our fathers would say: do it right the first time.

\section{The Future of NEPA}

In 2017, President Trump signed an Executive Order directing that the environmental review for major infrastructure projects should be reduced to no more than two years. Exec. Order No. 13807, 82 Fed. Reg. 40,463, 40,464 (Aug. $24,2017)$. Shortly thereafter, the Secretary of the Interior ordered agencies within the Department of the Interior to limit EISs to no more than 150 pages or 300 pages for "unusually complex projects." The Secretary also directed agencies to "complete each Final EIS . . . within 1 year from the issuance of a Notice of Intent (NOI) to prepare an EIS." He further directed each Interior agency to propose page limits and time deadlines for EA preparation. Dep't of the Interior, Sec. Order No. 3355 (Aug. 31, 2017).

On June 13, 2019, the U.S. Forest Service proposed revisions to its NEPA regulations. As the Service explained, "[t]he proposed rule would contribute to increasing the pace and scale of work accomplished on the ground and would help the Agency achieve its mission to sustain the health, diversity, and productivity of the nation's forests and grasslands to meet the needs of present and future generations." 84 Fed. Reg. 27544. The proposed rule would, among other things: allow the Service to use multiple CEs to authorize separate but dependent portions of a larger single project; narrow what must be considered when determining whether "extraordinary circumstances" require preparation of an EA or EIS; create a CE for treatment of up to 11.4 square-miles provided that no more than 6.5 squaremiles includes commercial or non-commercial timber harvest; and remove actions 
that modify roadless and potential wilderness from the list of projects normally requiring an EIS.

On January 10, 2020, the CEQ issued a notice of proposed rulemaking announcing its intent to amend NEPA's implementing regulations, which apply to all federal agencies. $85 \mathrm{Fed}$. Reg. at 1684 . The proposed rule seeks to define away NEPA's hard look requirement, in part by imposing time limits and page restrictions. However, these revisions appear to be based on anecdote rather than data, and they are likely to result in more litigation and reversals rather than improved efficiency.

\section{Recommendations}

Overall, data supports the conclusion that NEPA is working more efficiently than its critics contend, and while reforms are always needed, we do not believe that aggressive "streamlining" is warranted. Indeed, page restrictions, time limits, and the like could make it more difficult to satisfy "hard look" requirements and cause increased litigation related delays.

If we do amend the regulations implementing the "Magna Carta" of environmental laws, DANIEL R. MANDELKER, NEPA LAW AND LiTIGATION § 1:1 (2d ed. 2014), we should have sufficient information to assess the effect of any changes that are made. To make changes to a system that we don't understand and with no way to accurately evaluate the effect of those changes is no way to run a business or a government. Regulatory changes should be grounded in fact and data if we are to avoid significant unintended consequences. This should begin by collecting and publishing data on the number and type of NEPA documents prepared by each agency as well as the time spent on the analysis and number of alternatives considered. Data should be organized to allow tracking of decisions to determine whether administrative challenges or litigation occur, and if so, the outcome that followed.

As the Forest Service noted in the preamble to its proposed NEPA regulations, the Service experienced a 39 percent reduction in all non-fire personnel since 1995 coupled with a dramatic shift in funding away from forest resource management. Reduced staffing and inadequate budgets is not unique to the Forest Service and appears to be a major cause of delays in NEPA completion. Fully staffing and funding agencies would allow agencies to do better work and complete 
that work faster. While supporting the passage of NEPA, Senator Jackson stated: "The future of succeeding generations in this country is in our hands." 115 Cong. Rec. 40417 (1969). As we look to the future, our fathers' words continue to resonate: do it right the first time, and do not confuse cheap with inexpensive. 